JRCICE2007-40051

\title{
CRASH ENERGY MANAGEMENT CRUSH ZONE DESIGNS: FEATURES, FUNCTIONS, AND FORMS
}

\author{
Michelle Priante \\ US Department of Transportation \\ Volpe Center \\ Cambridge, MA
}

\author{
Eloy Martinez \\ US Department of Transportation \\ Federal Railroad Administration \\ Washington, D.C.
}

\begin{abstract}
On March 23, 2006, a full-scale test was conducted on a passenger train retrofitted with newly developed cab and coach car crush zone designs. This test was conducted as part of a larger testing program to establish the degree of enhanced performance of alternative design strategies for passenger rail crashworthiness. The alternative design strategy is referred to as Crash Energy Management (CEM) where the collision energy is absorbed in defined unoccupied locations throughout the train in a controlled progressive manner. By controlling the deformations at critical locations, the CEM train is able to protect against two very dangerous modes of deformation: override and large scale lateral buckling.

The CEM train impacted a standing locomotive-led train of equal mass at $30.8 \mathrm{mph}$ on tangent track. The interactions at the colliding interface and between coupled interfaces performed as designed. Crush was pushed back to subsequent crush zones, and the moving passenger train remained in-line and upright on the tracks with minimal vertical and lateral motions.

This paper evaluates the functional performance of the crush zone components during the CEM test. The paper discusses three areas of the CEM consist: the leading cab car end, which interacts with a standing locomotive; the coupled interfaces, which connect the CEM non-cab end; and the trailing cab car end, which interacts with the attached trailing locomotive. The paper includes a description of the crush zone features and performance.

The pushback coupler must absorb energy in a controlled progressive manner and prevent lateral buckling by allowing the ends of the cars to come together. The deformable anticlimbers are required to resolve non-longitudinal loads into planar loads through the integrated end frame while minimizing the potential for override. The energy absorbers must absorb energy in a controlled progressive manner. The engineer's
\end{abstract}

space must be preserved so that the engineer can ride out the event. The passenger space must be preserved so that the passengers can ride out the event. The prototype CEM design presented in this paper met all the functional design requirements. This paper describes how the crush zones perform at three different interfaces. Areas for potential improvements include the design of the primary energy absorbers, the placement of the engineer's compartment, and the interaction between the last coach car and the trailing locomotive.

\section{INTRODUCTION}

The Federal Railroad Administration (FRA), with assistance from the Volpe Center, has been conducting research on passenger rail equipment crashworthiness to develop technical information needed by FRA to promulgate passenger rail equipment safety regulations $[1,2,3]$. The principal focus of passenger rail equipment crashworthiness research has been the development of structural crashworthiness and interior occupant protection strategies. The results of the research have also been used in the development of railroad procurement specifications $[4,5]$ and industry standards $[6,7]$.

In the CEM train-to-train test, a passenger train hit a standing locomotive-led train of equal weight at $30.8 \mathrm{mph}$ and preserved all of the occupied volume. In a similar test of conventional equipment, the passenger consist crushed 22 feet and lost space for approximately 46 passengers.

This paper reports on a post-test autopsy of the crush zones. The paper evaluates the functional performance of the crush zone components during the CEM test. For the test requirements for a CEM crush zone, each required CEM feature has associated functions. This paper discusses three areas of the CEM consist: the leading cab car end, which interacts with a standing locomotive; the coupled interfaces, which connect the CEM non-cab end; and the trailing cab car 
end, which interacts with the attached trailing locomotive. For each of these areas, several features are discussed in terms of their functional performance, as well as the form of the design.

\section{Train-to-Train Test Description}

In the train-to-train test, a moving cab car-led train impacted a standing locomotive-led train on tangent track at $30.8 \mathrm{mph}$ [8]. The locomotive-led train included two hopper cars, ballasted such that both trains weigh nearly the same. The cab car-led train included four coach cars and a trailing locomotive. The passenger car consist is typical of a commuter push-pull consist, with a locomotive at one end, leading into a city and a cab car at the other to lead away from the city.

CEM end structures were installed at both ends of each passenger car. The interfaces contacting a locomotive (front end of the lead cab car and rear end of the coach car adjacent to the rear of the locomotive) had cab car CEM end structures that included such features as a deformable anti-climber, pushback engineer's compartment, and crushable components.

During the test of CEM equipment, all of the engineer and passenger space was preserved, override and lateral buckling of both the impacting and coupled equipment were prevented, and the train remained on the tracks. Overall, the energy of the collision was successfully managed.

\section{Crush Zone Components}

In the test, two types of crush zones existed: cab end and non-cab end. Three types of interfaces existed: impacting cab car, coupled non-cab car, and a coupled cab car. Figure 1 shows the FRA prototype cab end crush zone design that was developed as part of the research. The crush zone does not have exterior skin in this picture. The cab car crush zone includes several elements:

- A pushback coupler mechanism

- Deformable anti-climbers

- Non-deformable anti-climbers

- Integrated end frame

- Energy absorbers

- Engineer's compartment [9]

A similar design was developed for non-cab end crush zones. The non-cab end design does not include the deformable anti-climber or incorporate the engineer's compartment. The pushback coupler of the non-cab end crush zone has a shorter stroke than the cab end crush zone. The pushback coupler of the cab end crush zone was designed with sufficient stroke to accommodate an impact with a conventional cab car or locomotive.

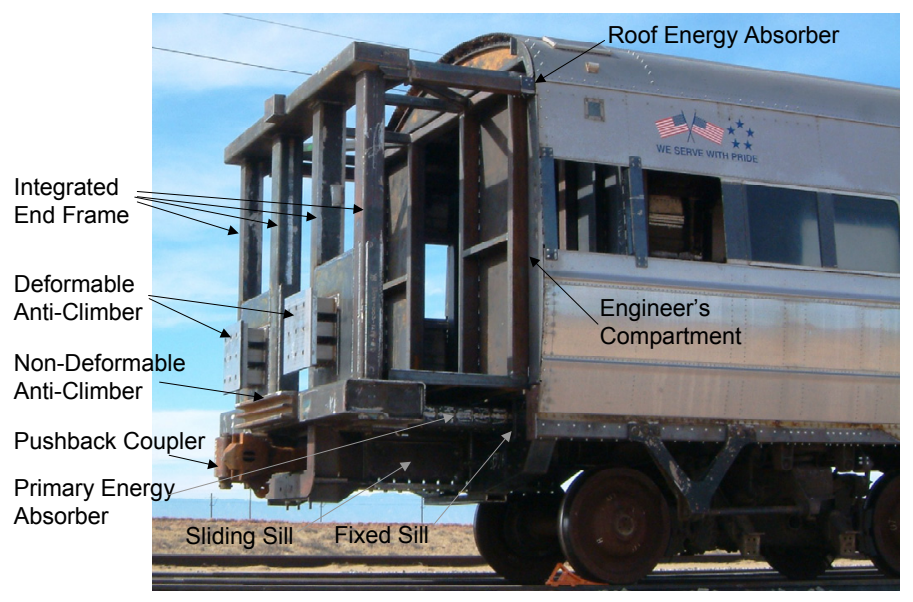

Figure 1. Cab Car Crush Zone

The two features that help manage the colliding interface interaction are the pushback coupler and the anti-climbers. The coupler experiences collision forces first. The coupler pushes back after a prescribed load range is reached and absorbs some of the collision energy. As the coupler pushes back, it eventually allows the load to transfer directly to the car's underframe and end frame components. The second key feature is a non-deformable anti-climber to allow vertical interlock after the pushback couplers have activated for the case where like cab cars, or a cab car and a coach car, are coupled. The cab car is equipped with a deformable anti-climber mounted to an integrated end frame structure to assist in the management of the colliding interface. The deformable anti-climber extends laterally between the collision and corner posts and vertically between the bottom of the window shelf member and the top of the buffer beam. The purpose of this integrated structure is to distribute the collision forces into the end frame and then back into the roof and underframe.

The collision and corner posts are connected into the buffer beam and the anti-telescoping plate, and they are tied together on each respective half by the shelf and deformable anti-climber support structures. These components are designed compliant with the American Public Transportation Association strength and deformation requirements. Another feature of this design is a rigid compartment to enable the engineer to safely ride out the collision. This space must include the engineer's seat, the control stand, and other equipment typically found in a cab car.

The integrated end frame is securely attached to a sliding sill that is connected to a fixed sill through a set of shear bolts. The purpose of the fixed sill/sliding sill assembly is to allow guided longitudinal pushback of the integrated end frame. This pushback motion enables the energy absorbers to be compressed between the relatively rigid sliding components and the fixed components in the occupied area of the car.

The energy absorbing elements include a secondary energy absorber placed behind the pushback coupler, a set of primary energy absorbers located at the level of the underframe, and a set of roof absorbers connected between the 
anti-telescoping plate and the fixed part of the roof structure within the confines of the occupied area of the car.

Having described the components of both a cab and coach crush zone design, the performance of the crush zones at three different interfaces is now discussed. Areas for potential improvement to the design are also discussed.

\section{First Interface Type: Impacting Cab Car End}

The impact cab car end performed as designed during the test. The coupler pushed back, the deformable anti-climbers conformed to the shape of the locomotive hood, and the engineer's compartment pushed back while the primary energy absorbers and roof absorbers absorbed collision energy in a progressive controlled fashion.

Coupler Two cracks were observed in the coupler of the leading cab car. Both were observed on the coupler's top side. In Figure 2, the top picture shows a crack located on the left side (as you are looking from the front of the car end) between the coupler head and shaft. The crack in the bottom picture is on the right side of the coupler head.
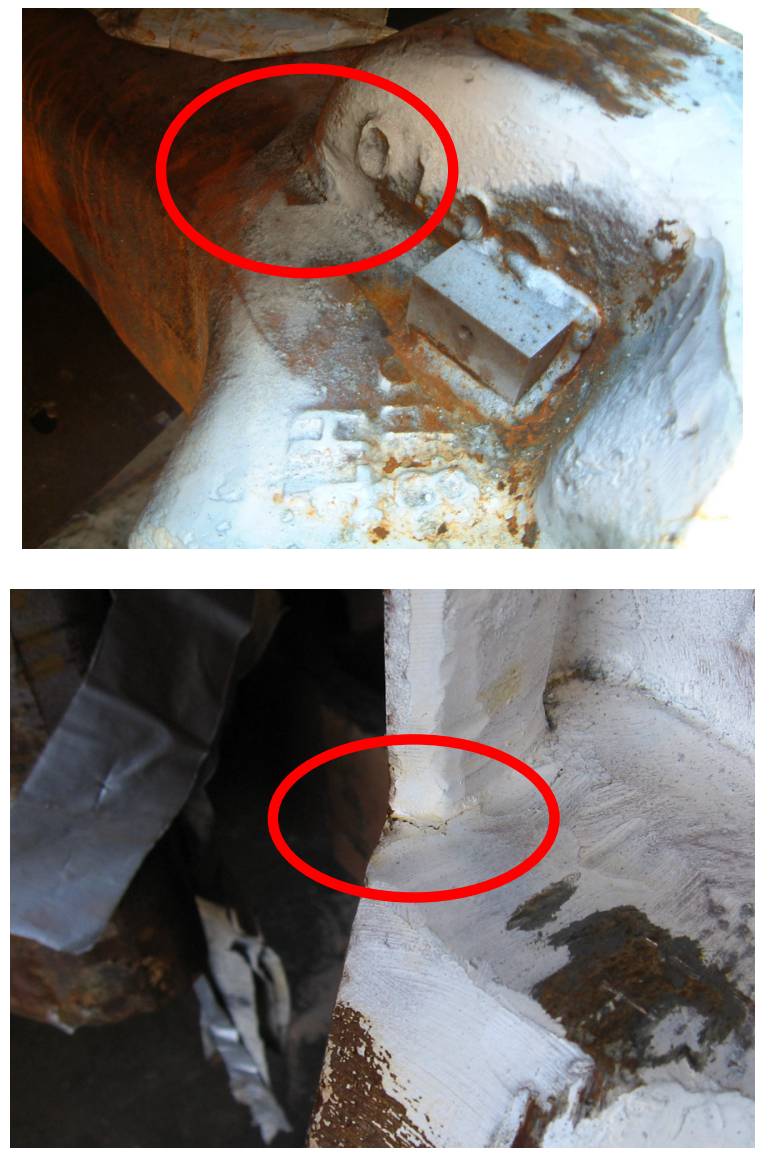

Figure 2. Cracks in the Coupler Head
The coupler pin, which connects the coupler yoke to the draft gear and allows the coupler to yaw, interfered and indented the plate above it. Figure 3 shows the indentation in the plate made by the coupler pin. Figure 4 shows the indentation on the coupler pin. Had the pin interfered sufficiently, such that it stuck on this plate, the coupler would not have pushed back as planned. This event could have resulted in lateral buckling at the colliding interface and the end frame mat not have engaged directly with the front of the impacting locomotive.

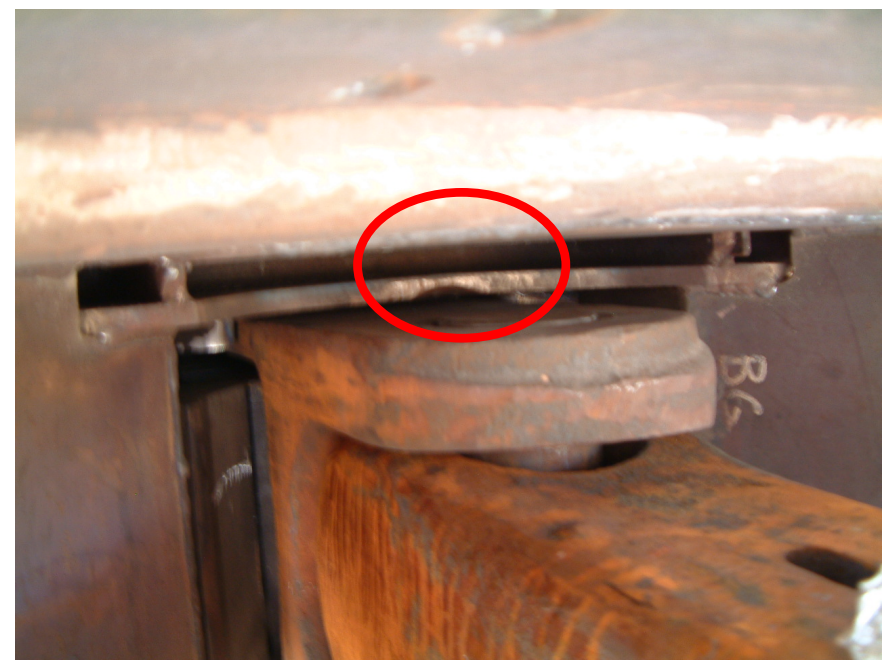

Figure 3. Plate Indented by the Coupler Pin

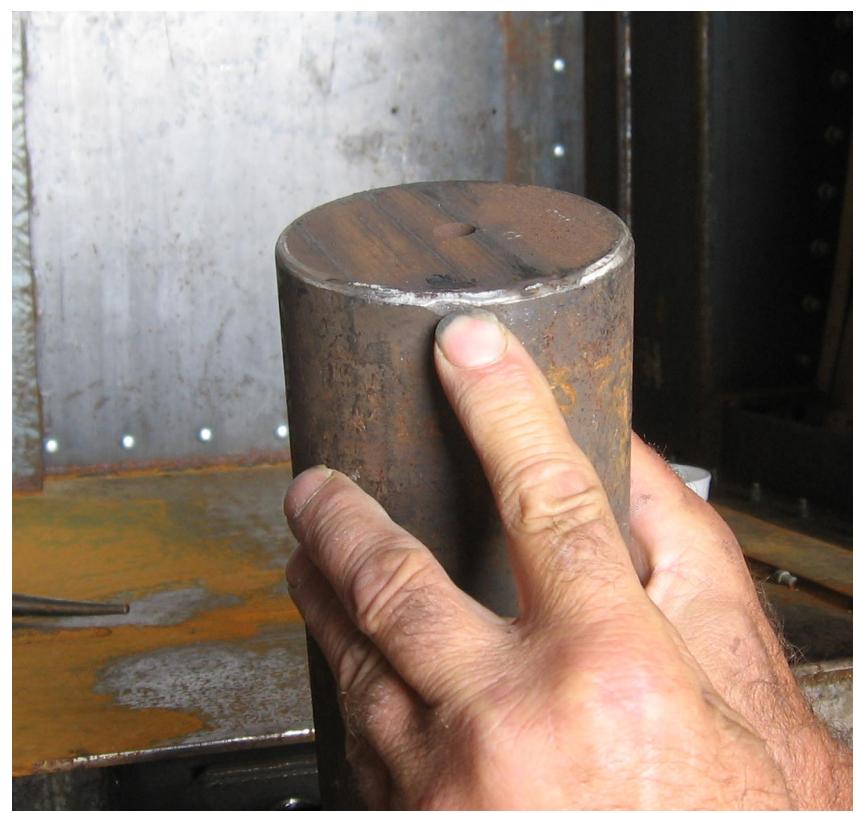

Figure 4. Indentation on Coupler Pin

When the force on the coupler due to the collision reaches a prescribed level, shear bolts fail, allowing the honeycomb in the buff lug to crush and absorb energy. In Figure 5, the buff 
lug has been cut to reveal the manner in which the honeycomb crushed. Even though the honeycomb in the pushback coupler crushed unevenly, the top of the honeycomb is level. While the honeycomb stayed in line and absorbed energy, the uneven crushing may lead to less coupler stroke or energy absorption at a higher load level than anticipated.

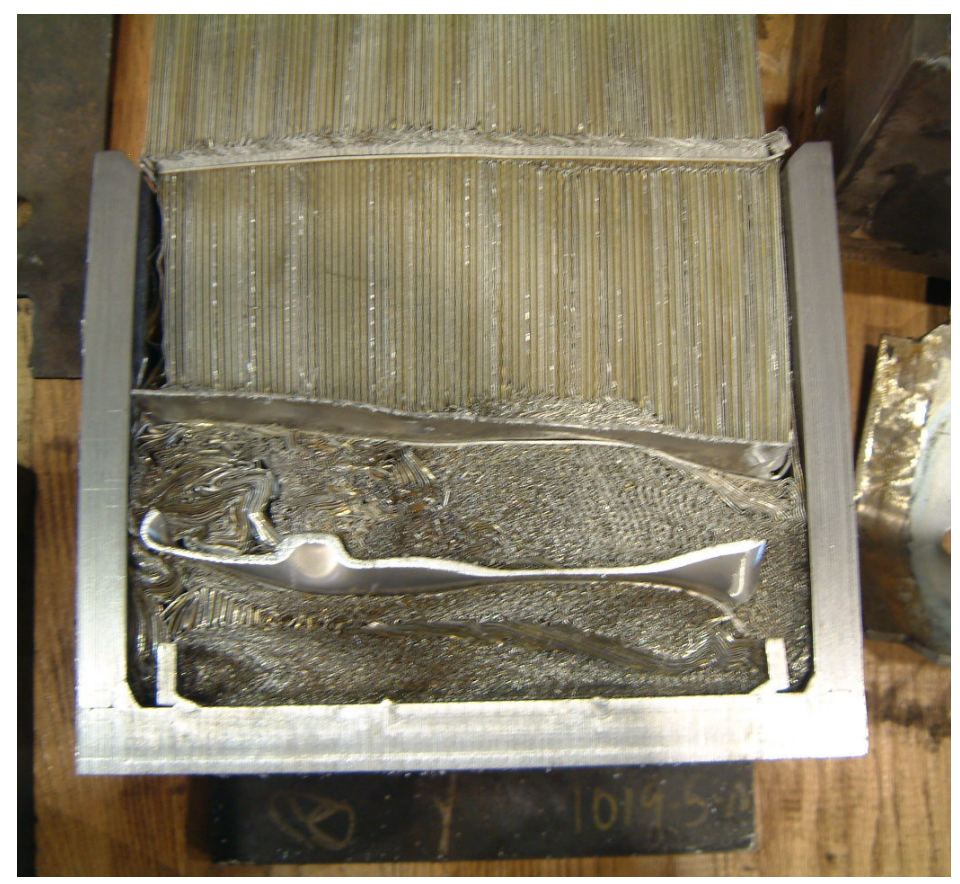

Figure 5. Honeycomb in the Buff Lug for the Pushback Coupler

When the buff lug was cut open during the post-test autopsy, evidence of poor welding was found. Figure 6 shows the poor welds. Oversight should be used in manufacturing these components.

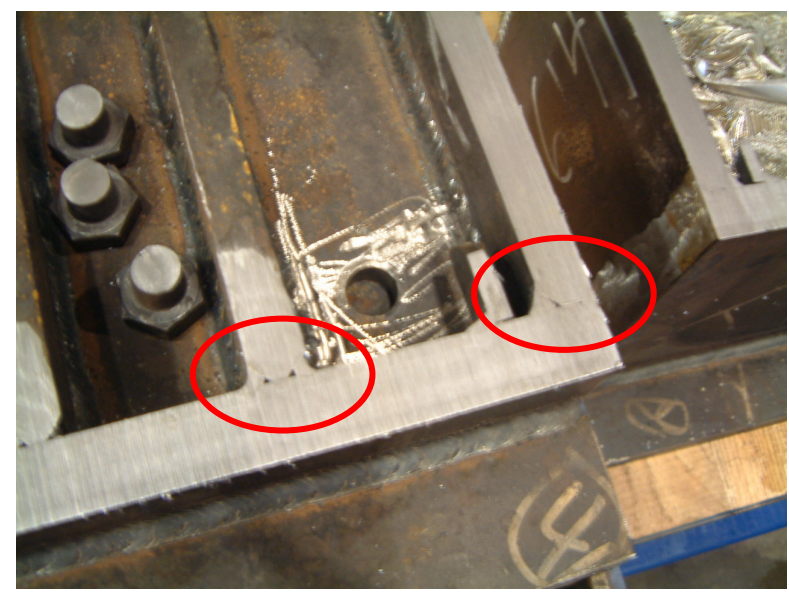

Figure 6. Evidence of Poor Welding Practices Found in the Buff Lug Welds
Deformable Anti-Climbers The deformable anticlimbers resolve non-longitudinal loads into planar loads through the integrated end frame while minimizing the potential for override. The design requirements do not allow material failure, since the component is required to resist longitudinal, lateral, and vertical loads. Figure 7 shows results from component tests in which the material did and did not fail. The stainless steel tubes were annealed to prevent material failure.
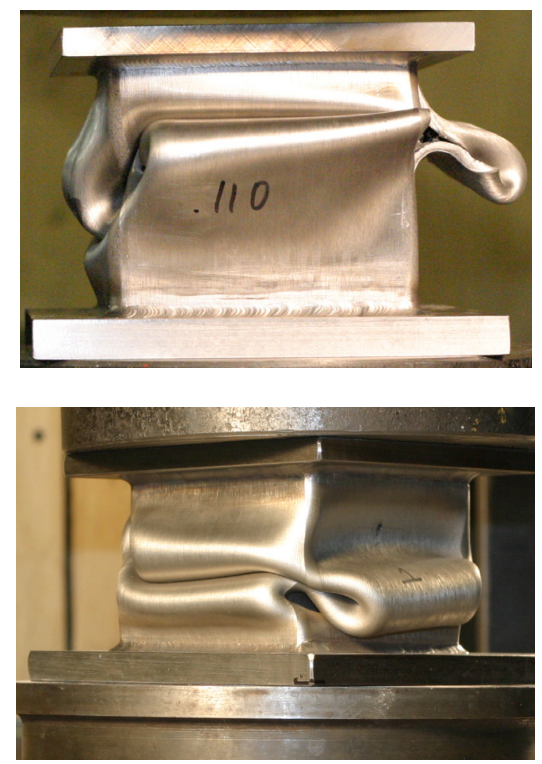

Figure 7. Component Testing for the Deformable AntiClimber: Material Failure (Top) and No Material Failure (Bottom)

A post-test photo of the deformable anti-climbers, Figure 8 , taken in three stages from a bird's eye view at the interaction between the cab car and the locomotive, shows that no material failure occurred in the deformable anti-climbers during the test. The deformable anti-climbers used multiple annealed stainless steel tubes with honeycomb cores. The tubes were connected to a waffle plate, which distributed the load from the cab car into multiple tubes. The deformable anti-climbers conformed to the shape of the locomotive.

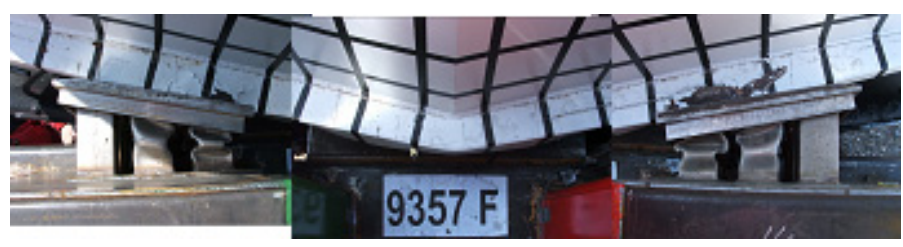

Figure 8. Bird's Eye View of the Deformable AntiClimbers and the Impacting Locomotive, Post-Test

Primary Energy Absorbers The primary energy absorbers performed acceptably during the test, however, they crushed less than expected. Additionally, the primary energy 
absorbers experienced material failure in the form of fracture. Figure 9 shows one set of primary energy absorbers after the train-to-train test. The primary energy absorbers in this picture crushed in a manner typical for all the primary energy absorbers. The bottom of the energy absorber has fractured. The primary energy absorbers must absorb energy in a controlled progressive manner. The amount of energy they absorb and the force level at which they absorb energy must enable the crush to be pushed back to subsequent interfaces. The energy absorbers are not required to take vertical or lateral loads, this is required through the fixed and sliding sills. Fracture is allowed in the energy absorbers, as long as the deformation mode is repeatable and the appropriate amount of energy is absorbed consistently. Due to the large amount of fracture seen in these components, future designs should minimize the potential for material failure.

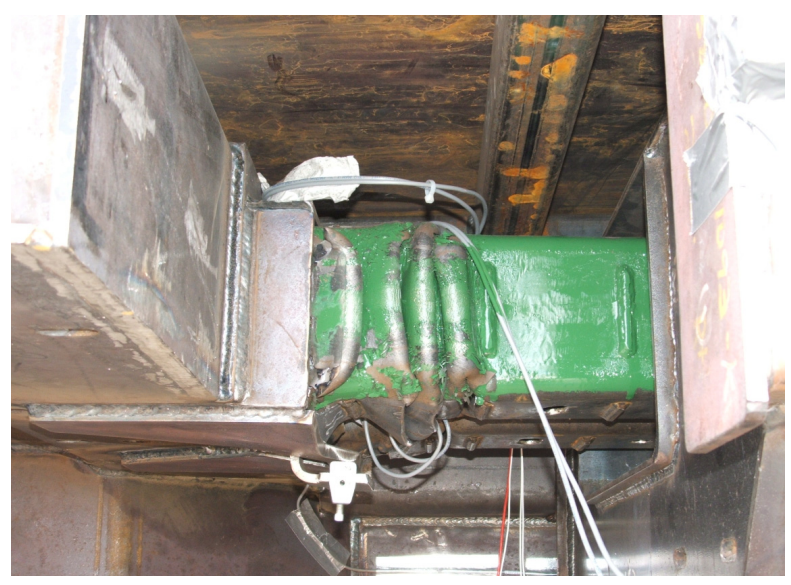

Figure 9. Primary Energy Absorbers, Post-Test

The engineer's compartment must be preserved so that the engineer can ride out the event. Figure 10 shows results from a model of the engineer's compartment in the undeformed state and once the system has been exhausted. In this design, the engineer's compartment is placed on top of the crush elements. Controlled crush occurs in the service closet, directly behind the engineer.

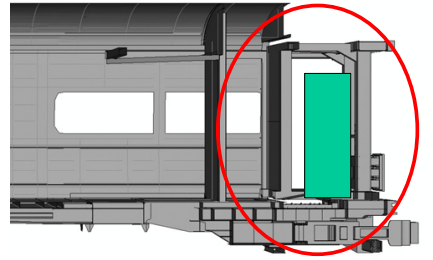

Undeformed State

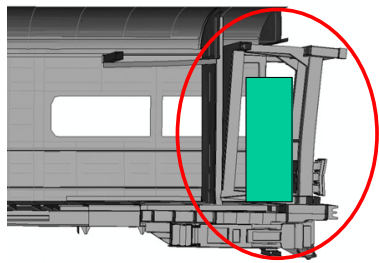

System Exhausted
Figure 10. Model Showing the Engineer's Compartment in the Undeformed State and Once the System Has Been Exhausted
Figure 11 shows the engineer's compartment at the colliding interface after the test was performed. The system was not exhausted in the test, and all the space for the engineer was preserved. This design met the test requirements. Alternative designs are possible, including a nose on the front end and placing the engineer's compartment behind the crush elements.

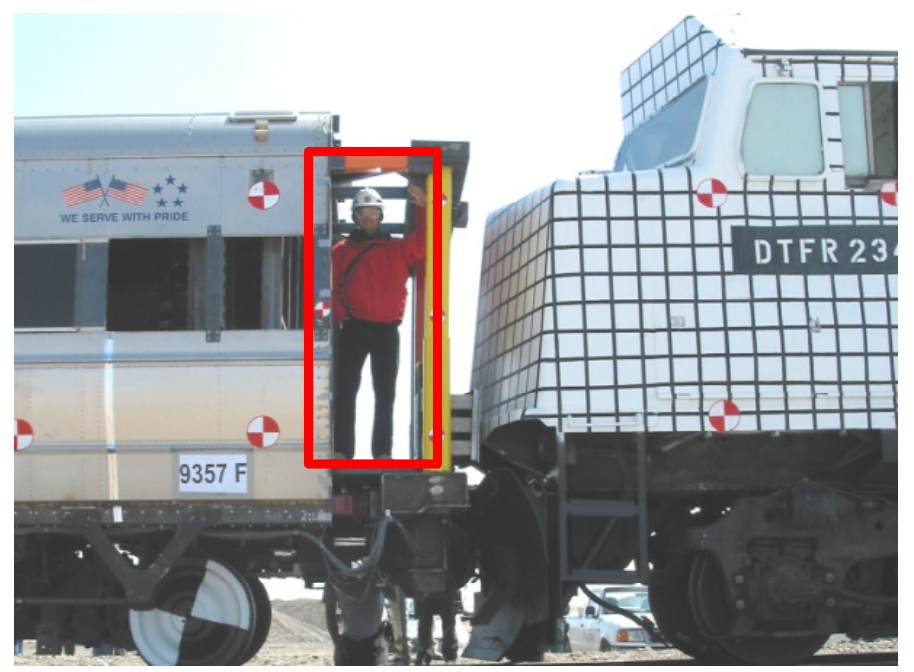

Figure 11. Engineer's Compartment, Post-Test

\section{Second Interface Type: Coupled Interfaces}

Coach car crush zones were utilized at all inter-train coupled interfaces. The non-cab crush zone is similar to the cab end crush zone but has fewer features. Non-cab end crush zones do not have deformable anti-climbers or an engineer's compartment. Non-cab crush zones were previously tested in the one-car and two-car test of CEM equipment [10]. The coupled interfaces behaved appropriately during the collision.

Figure 12 and Figure 13 show a typical coupled interface pre- and post-test. The post-test photo is a closeup view of the coupler, primary energy absorbers, and interlocking conventional anti-climbers. The crush zones remained inline laterally and vertically during the collision at all coupled interfaces. 


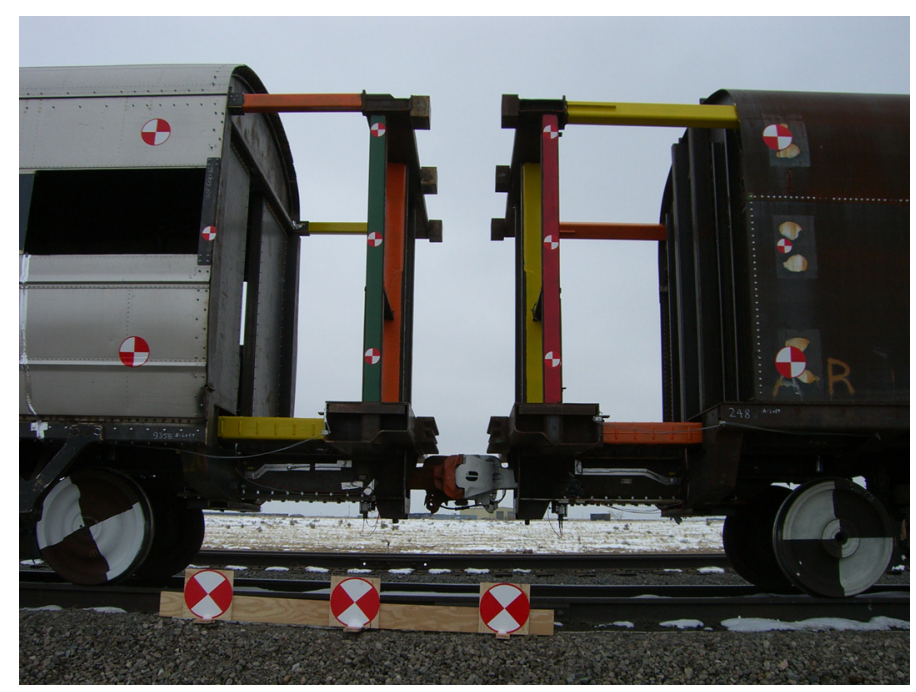

Figure 12. Coupled Interface Pre-Test

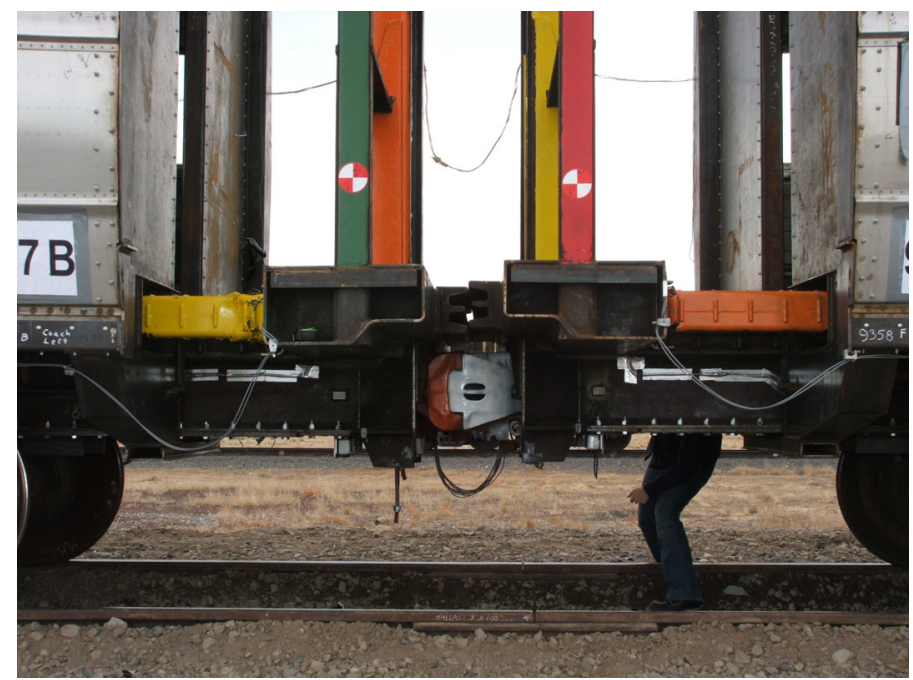

Figure 13. Coupled Interface Post-Test

Couplers In the non-cab ends, the pushback couplers must absorb energy in a controlled progressive manner and prevent lateral buckling by allowing the ends of the cars to come together. By allowing the car ends to come together, the collision load is distributed over a large area. In the test, the couplers triggered appropriately, and the car ends engaged. Figure 14 shows the couplers at one of the interfaces, post-test. The couplers have pushed back into the coupler housing, and lateral buckling has been prevented.

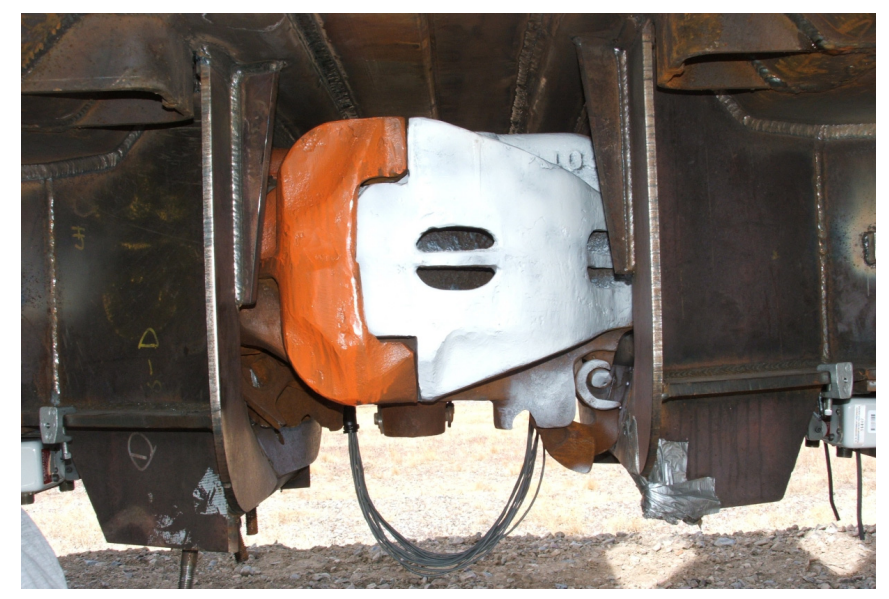

Figure 14. Couplers After They Have Pushed Back into the Coupler Housing

During the test, some of the couplers unexpectedly uncoupled after their initial impact. A coupler lifting link is on the underside of the coupler. When the pin is lifted, the cars can uncouple. Figure 15 shows the coupler lifting link. The top and middle pictures are side views of the coupler and the bellmouth. The middle picture shows a hand lifting the lifting link. During the test, the coupler carrier applied a force in approximately the same position. The bottom picture is a worm's eye view of the coupler and bellmouth. The uncoupling did not affect the crashworthiness of the train or the design requirements for the coupler. Addressing this detail, however, would easily prevent the uncoupling.
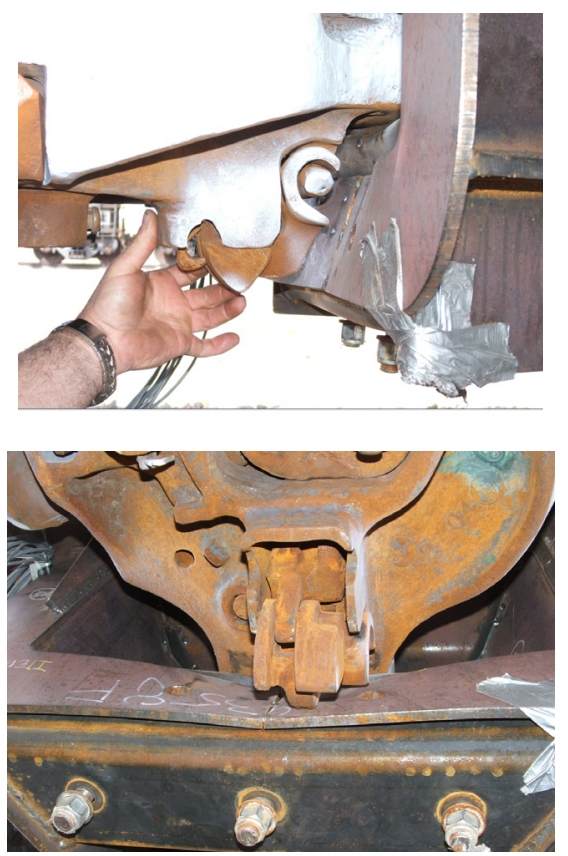

Figure 15. Interaction of the Coupler Lifting Link with the Coupler Carrier 
Passenger Volume/Side Sills During the test, the passenger volume was preserved. The Budd M1 carbody side sills buckled before the exhaustion of the crush zone energy absorbers. Figure 16 shows one of the side sill buckles. Figure 17 shows a closeup of the side sill buckle. The center sills were not damaged. The damage to the side sills occurred between the body bolsters. The cars were not modified between the body bolsters during the CEM retrofit. Outside of the body bolsters, near the crush zones, modifying the cross-section to be a closed section strengthened the side sills. It was also noted post-test that at the location of the buckle, a gap is in the welding.

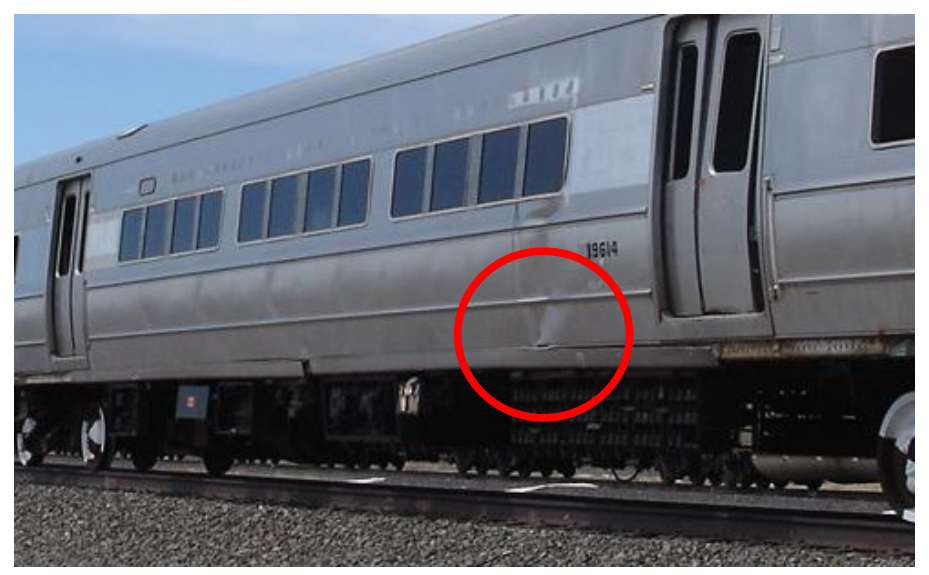

Figure 16. Side Sill Buckle in Budd M1 Car 9614

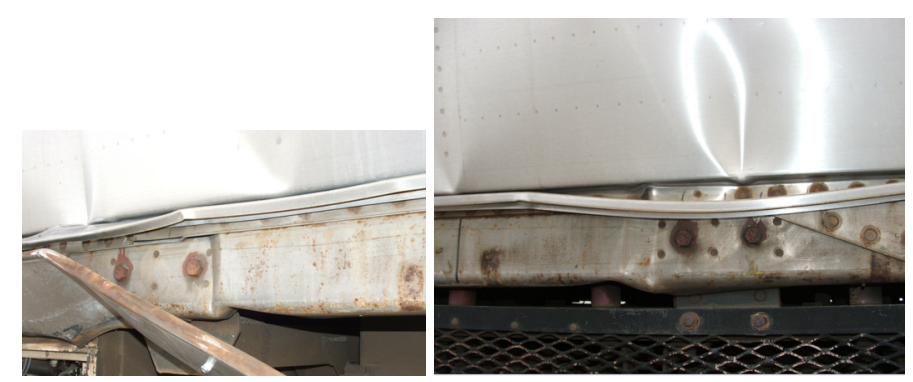

Figure 17. Closeup View of Side Sill Buckle

\section{Third Interface Type: Coupled Cab Car}

During the test, the trailing cab car and the trailing locomotive came together and deformed in an unexpected manner. The cab car coupler has a long stroke to allow for an interaction with the trailing locomotive coupler, crushed the honeycomb but also rotated slightly to the side. This lateral motion was due to the rotation of the rear locomotive coupler, which cannot pushback. The rear locomotive moved laterally and contacted the cab car off center. The on-car video from the cab car and post-test photographs show that the trailing cab car and the trailing locomotive contacted each other at a lateral offset. In addition, a side view camera of the interface shows that the trailing locomotive experienced vertical motions.
Figure 18 shows the trailing cab car and the trailing locomotive, post-test. In this picture, the deformable anticlimbers are in contact with the locomotive skirt. The locomotive skirt has deformed. The locomotive coupler is visible, but the cab car coupler has pushed back into the coupler housing and is not visible.

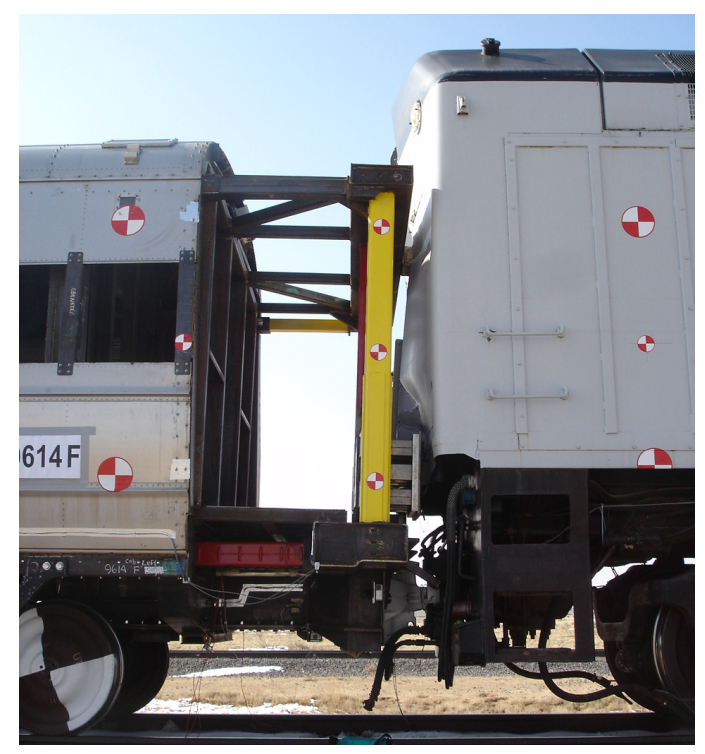

Figure 18. Trailing Cab Car and Trailing Locomotive, PostTest

Coupler The cab car coupler did pushback all the way during the test, as Figure 18 shows. However, the trailing locomotive moved laterally, and the coupler did not remain in line. A modification would be to install a pushback coupler on the trailing locomotive.

Sliding Sill/End Frame Connection Figure 19 is an overhead schematic of the trailing cab car, post-collision. Once the locomotive contacted the crush zone laterally off center, the roof tubes bent, and the end beam rotated. The roof tubes bent to the side during impact. The end beam bent at an angle to the car, deforming the connection between the fixed sill and the end beam. The primary energy absorbers crush different amounts, corresponding to the rotation in the end beam. The fixed sill stayed inline, relative to the car. The sliding sill made scraping marks on the inside of the fixed sill as it pushed back. 


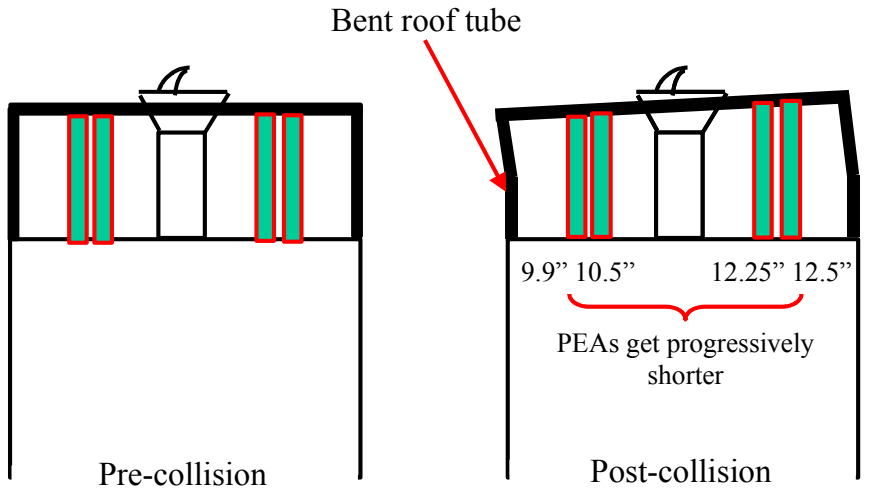

Figure 19. Overhead Schematic of the Trailing Cab Car End Crush Zone, Pre- and Post-Test

The entire sliding sill twisted at an angle, relative to the end frame. In Figure 20, the crush zone has been removed from the trailing cab car. The front of the crush zone is resting on level ground, on the anti-climber. In this bottom view, it is clear that the sliding sill is twisted relative to the end frame.

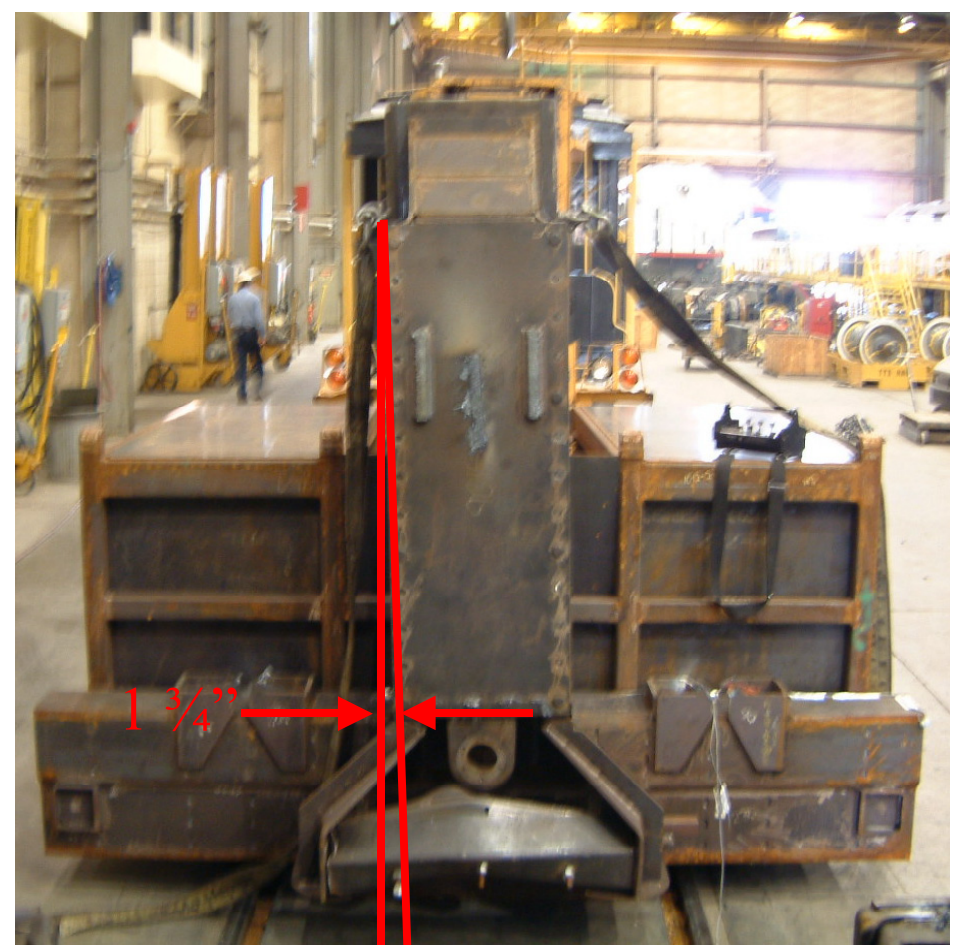

Figure 20. Bottom View of the Sliding Sill

The end frame twisted at an angle during the collision. The trailing locomotive coupler was initially attached to the trailing cab car coupler. During the collision, when the force was transmitted from the cab car to the locomotive, the cab car coupler crushed inline, and the locomotive coupler began to buckle laterally. The skirt of the locomotive hit the anticlimber of the cab car off center. Figure 21 shows the contact area between the locomotive and the anti-climber on the cab car.

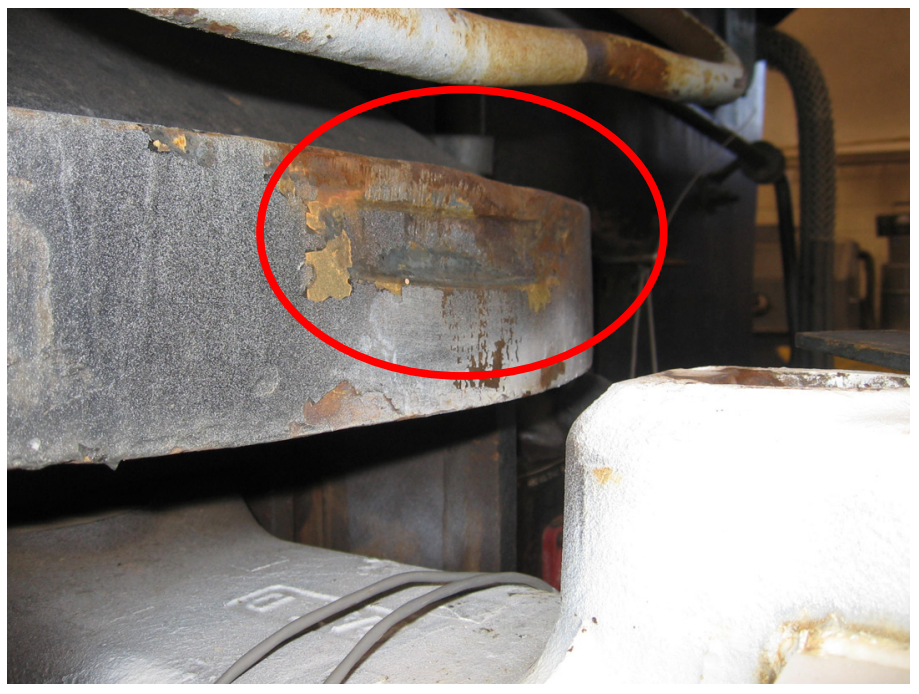

Figure 21. The Locomotive Edge Where It Hit the AntiClimber

Additional design form issues existed with the sliding sill and buffer beam connection on the cab end crush zone of the trailing cab car. For the interface between the trailing cab car and the trailing locomotive, the functional requirements were to control vertical and lateral movements. In the vertical direction, the ends of the locomotive and cab car have to engage and not allow override. For lateral movement, the cab car and locomotive have to remain in-line and on the track, and no lateral buckling can occur. These requirements were met. The design of the trailing cab car performed well at the colliding interface and the load enters as designed.

Some unexpected fracture occurred in the trailing end crush zone. A vertical movement in the locomotive put a downward force on the deformable anti-climber that caused unexpected fracture. The fracture occurred at a designed cutout in the connection between the sliding sill and the buffer beam. An opening is the connection between the cab car sliding sill and the buffer beam. This opening creates a stress concentration in an area that experiences high loads. In general, care should be taken to avoid stress concentrations in areas that experience high loads. Stress concentrations facilitate fracture. Figure 22 shows the connection. 


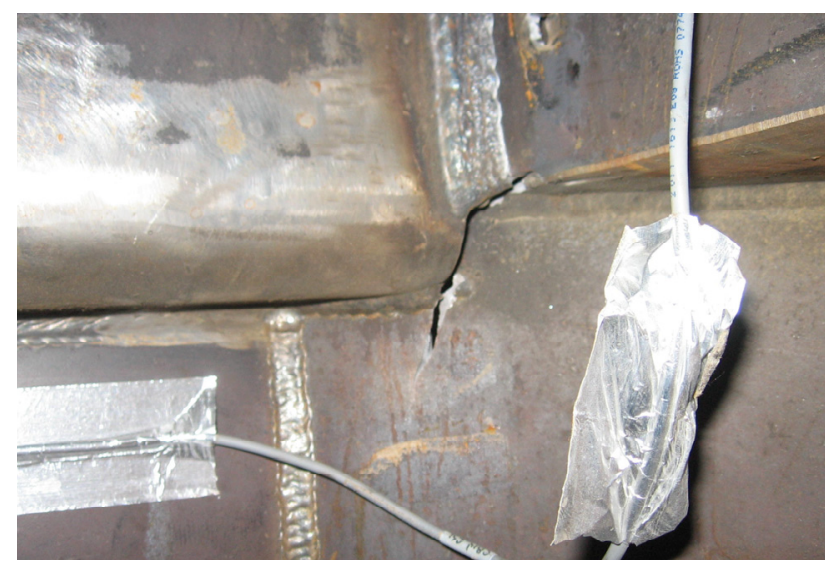

Figure 22. Crack on the Outside of the Bellmouth

Under very high loads, a crack formed in the bellmouth, allowing the end frame and the sliding sill to twist at an angle, as shown in Figure 20. Figure 23 shows the crack in the coupler carrier. In the picture, the crush zone has been removed and is resting on the anti-climber on the front. The bellmouth is facing the ground. The bottom of the sliding sill has been removed, along with the draft gear, coupler, buff lugs, and honeycomb. The crack runs along the top of the bellmouth. The length of the crack is 1 foot, stretching from the connecting point of the top and side of the bellmouth across the top of the bellmouth.

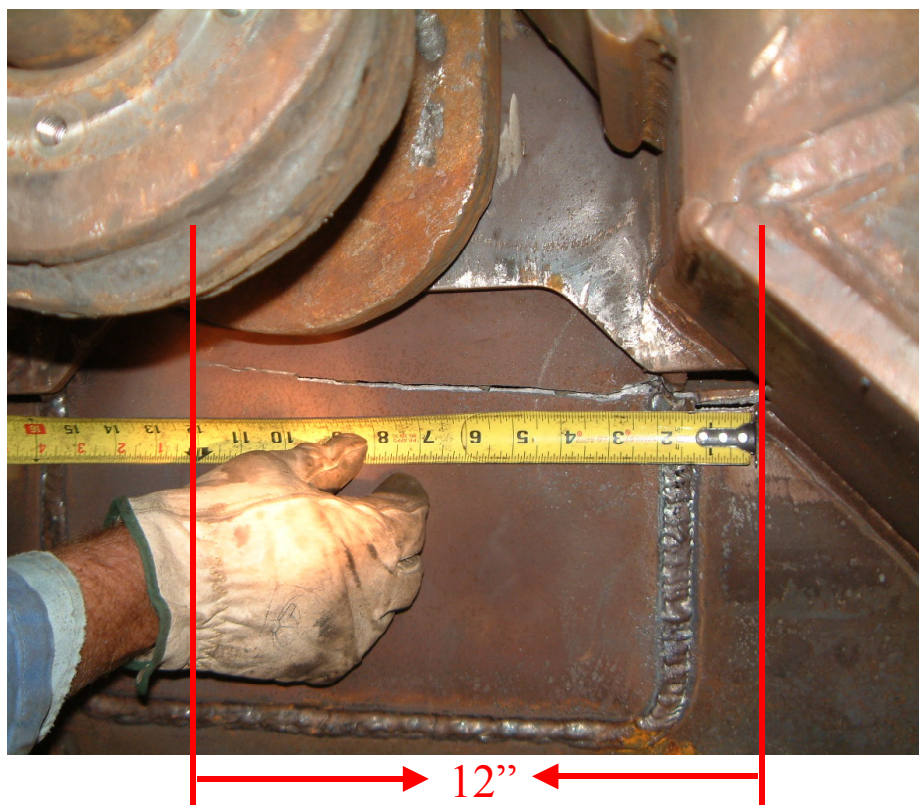

Figure 23. Crack on the Top of the Bellmouth

When the sliding sill slid into the fixed sill, the sides of the sills scraped against each other. Figure 24 shows the scraping along the inside of the fixed sill.

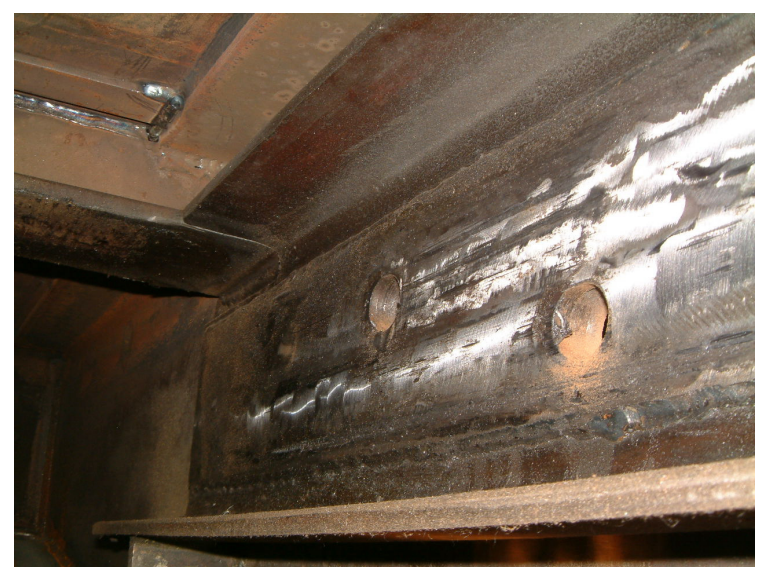

Figure 24. Signs of Scraping on the Fixed Sill Where the Sliding Sill Contacted

Coupler Carrier Figure 23 shows the bottom side of the coupler carrier after the coupler, draft gear, and buff lug have been removed. The crack spans two pieces of metal in this photo. The total crack length on this side is 12 inches. Below is a closeup view of the crack. This picture also shows a clear view of the material gap in the connections between several plates, at the right side of the crack. The gap created a stress riser in the coupler carrier. This crack may have been avoided if the pieces were designed to connect without a gap.

Figure 22 shows the bellmouth crack, taken from the outer side of the bellmouth. The weld at the top center of the picture is stretched but is still holding. To the right of the stretched weld is one of several failed slot welds.

When the cracks in the bellmouth and coupler carrier formed, the slot welds near the crack failed. The slot welds connect the inner and outer plates of the end beam. The schematic in Figure 25 shows the locations of the failed slot welds. Figure 26 shows the failed slot welds. All welds should be properly made and inspected in order to prevent failure.

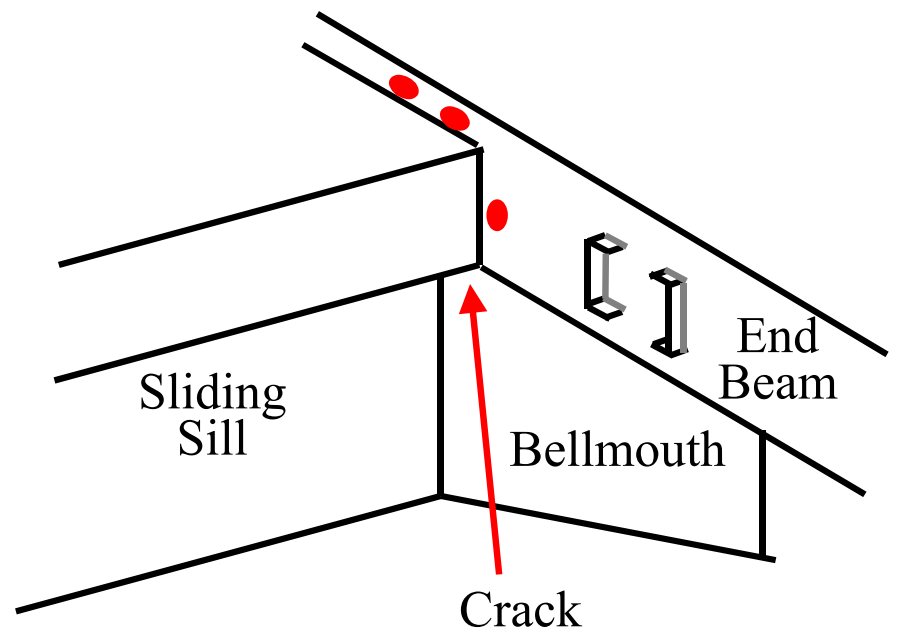

Figure 25. Schematic Showing the Location of the Failed Slot Welds 


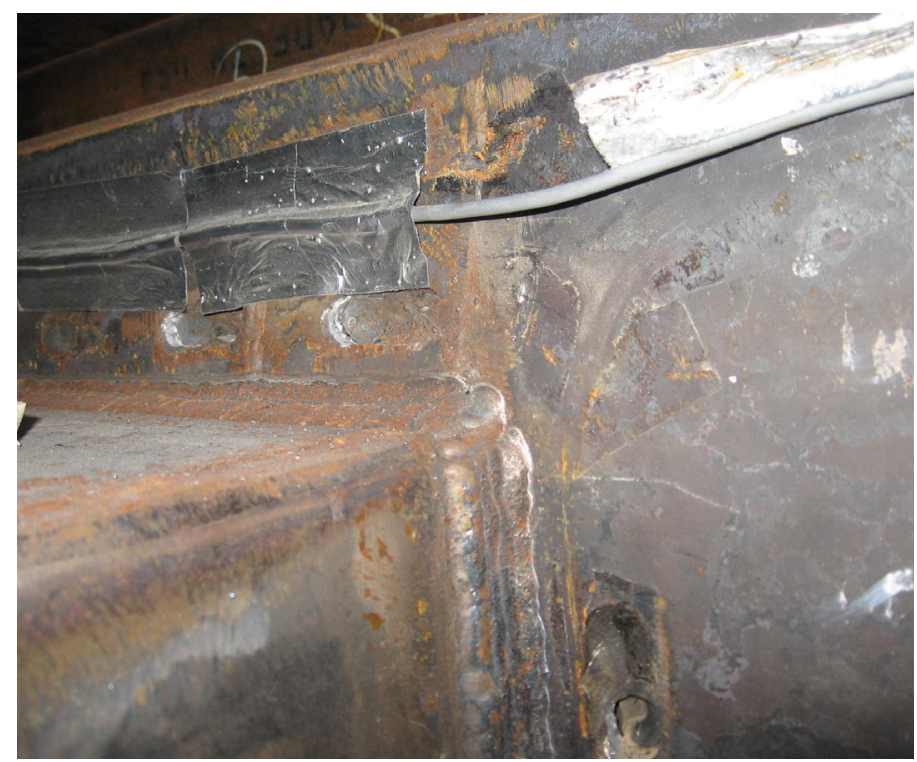

Figure 26. Three Failed Slot Welds

Deformable Anti Climbers/Locomotive Skirt The deformable anti-climbers in the trailing cab car crush zone behaved well with minimal crushing. Figure 27 shows pictures of the deformable tubes. The trailing locomotive was softer than the deformable anti-climbers. As shown in Figure 27, the deformable anti-climbers did not deform as much as the anticlimbers at the front end; instead the locomotive skirt crushed.

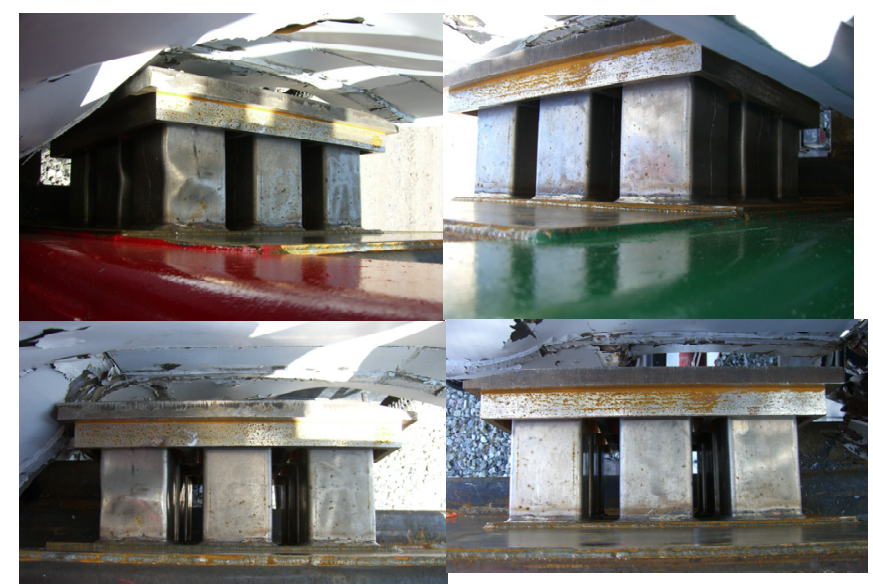

Figure 27. Two Deformable Anti-Climbers from Various Angles

Figure 28 shows the deformation at the interface between the trailing cab car and the trailing locomotive. This deformation was uncontrolled due to the folding of the locomotive skirt. The locomotive was not modified for this test.
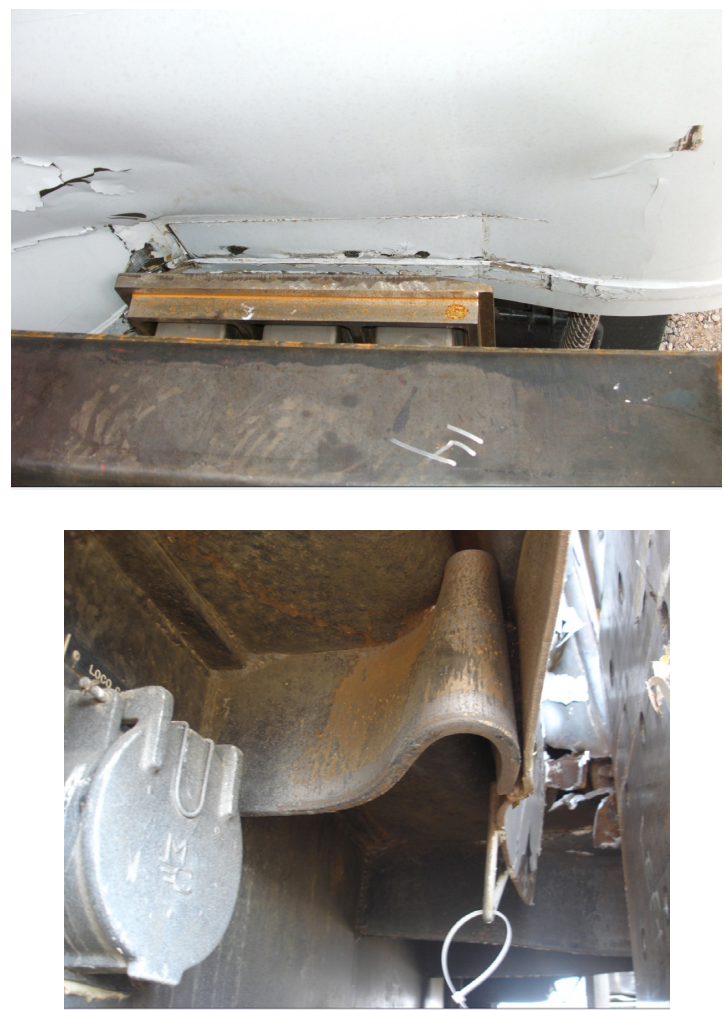

Figure 28. Deformation in the Trailing Locomotive Skirt

Primary Energy Absorber Attachment The primary energy absorbers were removed from the crush zone as part of the post-test autopsy. As shown in Figure 29, the splitting at the corners of the attachment interfered with the folding of the primary energy absorbers and contributed to the undesirable modes of deformation at the ends of the crush elements.

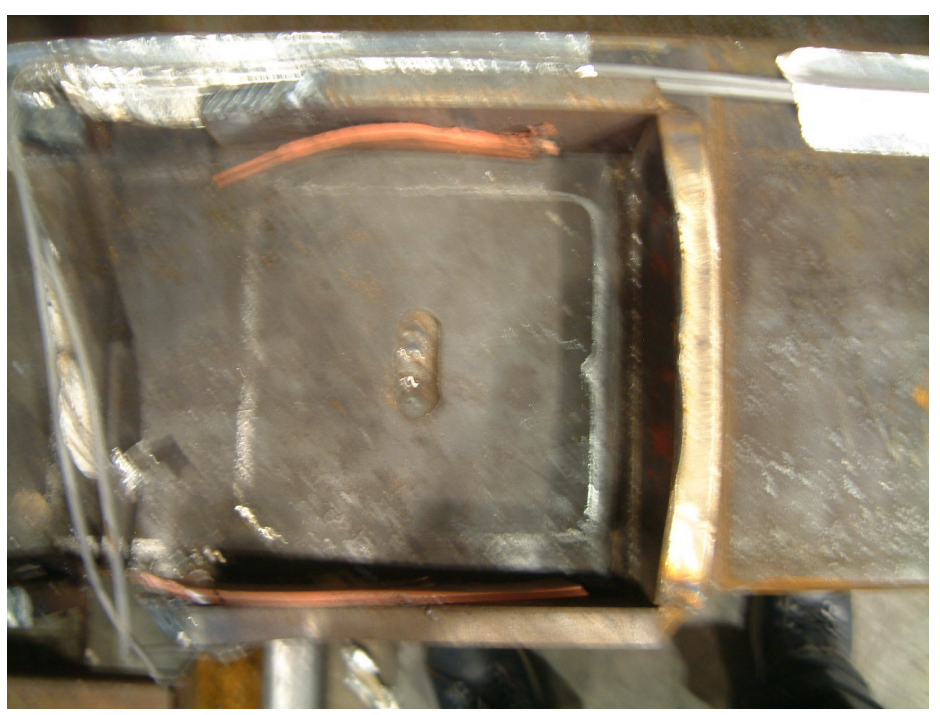

Figure 29. Bulging in the Primary Energy Absorber Attachment Plates 


\section{Summary}

The components have been evaluated based on the results of the full-scale test. While all the components met their functional requirements, some components may require redesign for a production version.

The deformable anti-climbers worked well and should be a feature of any cab car CEM system. The deformable anticlimbers were annealed and made with thin walls so as to deform with no material failure.

The pushback coupler design worked adequately. As shown in the post-test autopsy, the honeycomb does not crush evenly. This may affect the energy absorption capabilities for collisions with more energy. A redesign of the lifting link at the rear of the coupler head should be done for this type of pushback coupler.

The primary energy absorber design could be improved. Other methods for energy absorption should be explored. In general, material failure, although permitted in certain circumstances, should be avoided if possible. This may be accomplished by one or more of the following options: use thinner sections, use a ductile material, anneal if necessary, increase the number of energy absorbers, and redesign the placement of the energy absorbers.

\section{Conclusions}

The cab and coach car crush zones include all requisite features of a working CEM system:

- A pushback coupler mechanism

- Deformable anti-climbers arrangement

- Non-deformable anti-climbers

- Integrated end frames

- Energy absorbers

- Engineer's compartment

All the functions for each feature and the complete system were achieved. The design prototype that was built for this test, however, could be improved or redesigned, provided that the requisite functions are met.

\section{ACKNOWLEDGMENTS}

The research described in this paper was performed as part of the Equipment Safety Research Program sponsored by the Office of Research and Development of FRA. The authors would like to thank Claire Orth, Chief, Equipment and Operating Practices Division, for her support. Dr. Tom Tsai, Program Manager, led this effort. Gunars Spons, FRA Resident Manager at the Transportation Technology Center, managed the full-scale test effort. Grady Cothen, Deputy Associate Administrator for Safety Standards and Program Development, has coordinated FRA's regulations development and the passenger rail equipment crashworthiness research since the inception of this research.

Volpe Center staff David Tyrell, Senior Engineer; Benjamin Perlman, Senior Engineer; and Karina Jacobsen, Mechanical Engineer; for designing and managing the test.
Kristine Severson, Senior Engineer, and Daniel Parent, Mechanical Engineer, designed and managed the occupant portions of the test.

Matthew Witte, Senior Engineer, Transportation Technology Center Inc. (TTCI), led the TTCI team that implemented the test. Tom Roderick, Senior Technician; Joe Hanratty, Senior Technician; and Bruce Perrin, Senior Technician; integrated the crush zones into the cars.

METROLINK, the Los Angeles commuter railroad, in their ongoing procurement of passenger rail equipment, has applied the results of the CEM research.

\section{REFERENCES}

[1] Cothen, G., Schulte, C., Horn, J., Tyrell, D., "Consensus Rulemaking at the Federal Railroad Administration," TR News, Transportation Research Board, Number 236, January-

February 2005.

[2] Tyrell, D., "U.S. Rail Equipment Crashworthiness Standards," presented at 'What can We Realistically Expect from Crashworthiness?' Rail Equipment Crashworthiness Symposium, Institute of Mechanical Engineers, May 2, 2001, London, England.

[3] U.S. Department of Transportation, Federal Railroad Administration, "49 CFR Part 216 et al., Passenger Equipment Safety Standards; Final Rule,” Federal Register, May 12, 1999. [4] Tyrell, D.C., Severson, K.J., Marquis, B.J.,

"Crashworthiness of Passenger Trains," U.S. Department of Transportation, DOT/FRA/ORD-97/10, 1998.

[5] Tyrell, D., Martinez, E., Jacobsen, K., Parent, D., Severson, K., Priante, M., Perlman, A.B., "Overview of a Crash Energy Management Specification for Passenger Rail Equipment," American Society of Mechanical Engineers.

[6] American Public Transportation Association, Member Services Department, Manual of Standards and Recommended Practices for Passenger Rail Equipment, Issue of May 1, 2004. [7] Association of American Railroads, Technical Services Division, Mechanical Section-Manual of Standards and Recommended Practices, "Locomotive Crashworthiness Requirements, Standard S-580,” Adopted: 1989, Revised, 1994, Revised 2005.

[8] Tyrell, D., Jacobsen, K., Martinez, E., Perlman, A.B., "Train-to-Train Impact Test of Crash-Energy Management Passenger Rail Equipment: Structural Results," American Society of Mechanical Engineers, Paper No. IMECE200613597.

[9] Martinez, E., Tyrell, D., Rancatore, R., Stringfellow, R., Amar, G., "A Crush Zone Design for An Existing Passenger Rail Cab Car," American Society of Mechanical Engineers, Paper No. IMECE2005-82769, November 2005.

[10] Jacobsen, K., Tyrell, D., Perlman, A.B., "Impact Tests of Crash Energy Management Passenger Rail Cars: Analysis and Structural Measurements," American Society of Mechanical Engineers, Paper No. IMECE2004-61252, November 2004. 